\title{
AVMA opposes bill to prohibit the use of random-source cats and dogs
}

On 15 January 2006, the American Veterinary Medical Association (AVMA) announced its opposition to a bill that would prohibit the use of random-source dogs and cats in research and teaching ${ }^{1}$.

The 'Pet Safety and Protection Act of 2005' (S. 451) $)^{2}$, which was introduced by Sen. Daniel Akaka (D-HI) in February 2005 , is intended to protect family pets by preventing the sale or provision of randomsource dogs and cats to research facilities unless they meet specified requirements.

The AVMA's Legal Advisory Committee and Council on Research (COR) see S. 451 as "inconsistent with the AVMA Position Statement on Use of Random-Source
Dogs and Cats for Research, Testing, and Education, which states the carefully controlled use of random-source dogs and cats contributes greatly to improving the health and welfare of animals and humans ${ }^{1}$."

In its recommendations to the AVMA Executive Board, the COR pointed out that the Animal Welfare Act contains provisions to protect the safety of family pets, as well as the welfare of research animals.

1. AVMA. Executive Board coverage: randomsource cats and dogs. JAVMA News (15 January 2006). http://www.avma.org/onlnews/default 060115.asp.

2. S. 451. 'Pet Safety and Protection Act of 2005'. (17 February 2005).

\section{China prohibits unsupervised research on highly pathogenic microbes}

On 14 December 2005, China's chief veterinary officer announced that China will prohibit unsupervised research on highly pathogenic microorganisms. This decision followed the discovery by the government of several laboratories that conducted research on highly pathogenic microorganisms without government permission ${ }^{1}$.

Last year, China's State Council issued a national laboratory safety regulation that required research laboratories to meet specific standards for experimenting with pathogenic microorganisms and obtain the permission of the Ministry of Health and the Ministry of Agriculture for conducting such experiments.

1. China View. Unsupervised research on pathogenic microbes forbidden: officer. (14 December 2005). http://news.xinhuanet.com/ english/2005-12/14/content_3922907.htm. 